\title{
WIPP Facility Work Plan for Solid Waste Management Units
}

\author{
February 2000
}

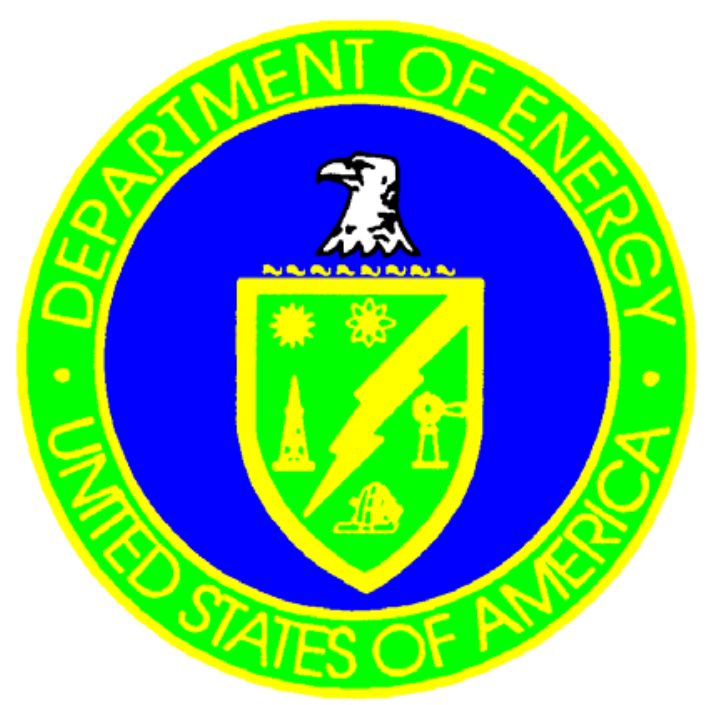

Processing and final preparation of this report was performed by the Waste Isolation Pilot Plant Management and Operating Contractor for the U.S. Department of Energy under Contract No. DE-AC04-86AL31950 


\section{TABLE OF CONTENTS}

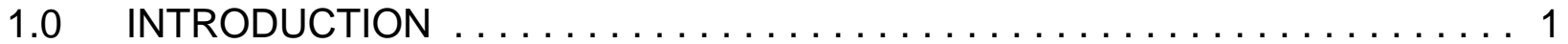

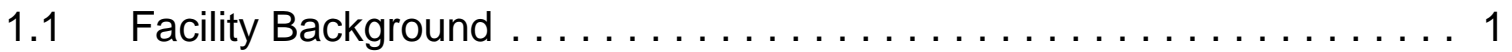

1.2 SWMUs and AOCs Identified in the Permit $\ldots \ldots \ldots \ldots \ldots \ldots \ldots 2$

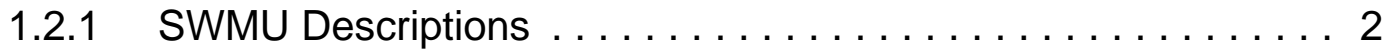

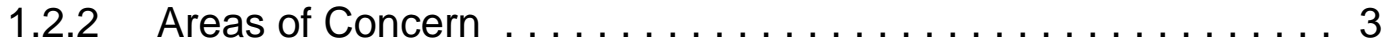

1.3 Work Plan Organization $\ldots \ldots \ldots \ldots \ldots \ldots \ldots \ldots \ldots \ldots$

2.0 PROJECT MANAGEMENT PLAN $\ldots \ldots \ldots \ldots \ldots \ldots \ldots \ldots \ldots \ldots$

2.1 Technical Approach, Schedules, Budget, and Key Project

Personnel ............................ 4

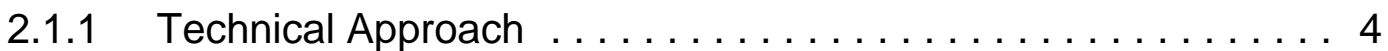

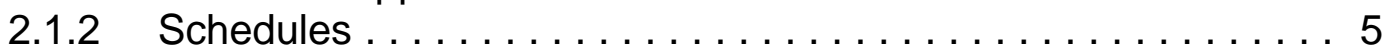

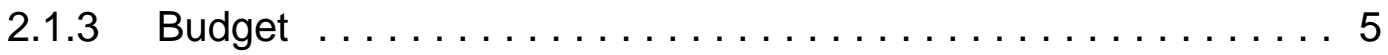

2.1.4 Key Project Personnel $\ldots \ldots \ldots \ldots \ldots \ldots \ldots \ldots \ldots \ldots$

$2.2 \quad$ Key Project Personnel Qualifications $\ldots \ldots \ldots \ldots \ldots \ldots \ldots \ldots 6$

2.3 Overall Management Approach to the RFI $\ldots \ldots \ldots \ldots \ldots \ldots$

3.0 DATA COLLECTION/QUALITY ASSURANCE PLAN $\ldots \ldots \ldots \ldots \ldots \ldots$

3.1 Data Collection Quality Assurance Strategy $\ldots \ldots \ldots \ldots \ldots \ldots \ldots 7$

3.1.1 Intended Data Uses . . . . . . . . . . . . . . . 7

3.1.2 Methods and Procedures to Assess Precision, Accuracy, and Completeness . .................... 8

3.1.3 Schedule and Information to be Provided in Quality

Assurance Reports ...................... 9

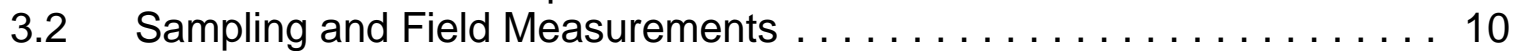

3.2.1 Selecting Sampling and Field Measurements Locations .... 11

3.2.2 Number of Sampling and Field Measurement Sites . . . . . . . 11

3.2 .3 Sampling Conditions ........................ 11

3.2.4 Measurement Parameters .................. 11

3.2.5 Frequency of Sampling, and Length of Sampling Period . . . . 12

3.2.6 Types and Number of Samples ................ 12

3.2.7 Procedures to Prevent Contamination ............. 12

3.2.8 Sampling Operations and Procedures $\ldots \ldots \ldots \ldots \ldots \ldots \ldots 12$

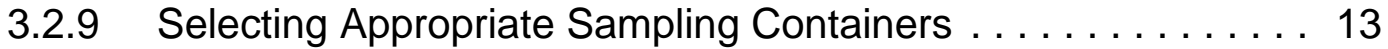

3.2 .10 Preserving Samples . . . . . . . . . . . . . . . 13

3.2.11 Controlling Chain-of-Custody . ................ 13

3.2.12 Disposing of Contaminated Materials Generated by

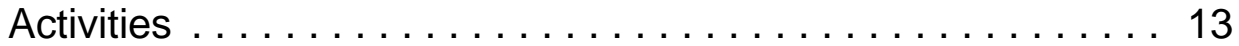

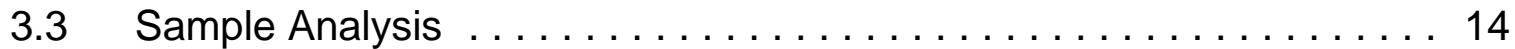

3.3.1 Chain-of-Custody Procedures $\ldots \ldots \ldots \ldots \ldots \ldots \ldots \ldots$

3.3.2 Sample Storage Procedures and Holding Times . . . . . . 15

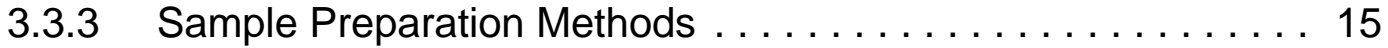

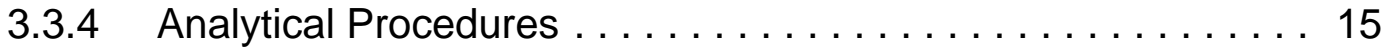

3.3.5 Calibration Procedures and Frequency $\ldots \ldots \ldots \ldots \ldots \ldots 15$

3.3.6 Data Reduction, Validation, and Reporting . . . . . . . . 15

3.3.7 Frequency of Internal Quality Control Checks and Laboratory Performance Audits 
4.0 DATA MANAGEMENT PLAN ....................... 19

4.1 Data Documentation Materials and Procedures $\ldots \ldots \ldots \ldots \ldots \ldots 19$

$4.1 .1 \quad$ Field Data . . . . . . . . . . . . . . . . . . . . . 19

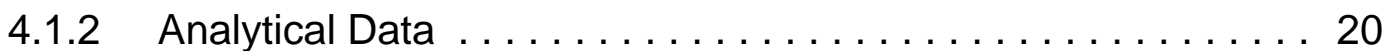

4.2 Project File Requirements . . . . . . . . . . . . . . . . . . 20

4.3 Project-Related Progress Reporting Procedures and Documents . . . 20

4.4 Data Records .............................. 21

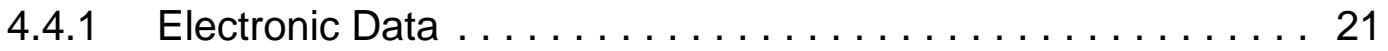

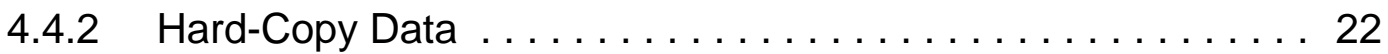

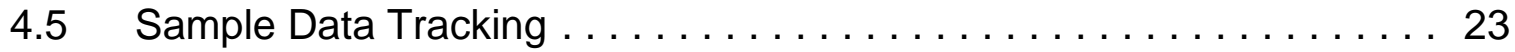

5.0 SITE SAFETY AND HEALTH PLAN $\ldots \ldots \ldots \ldots \ldots \ldots \ldots \ldots \ldots \ldots$

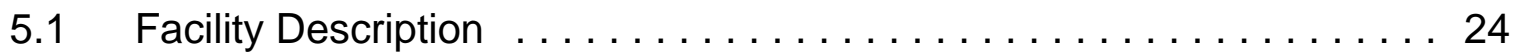

5.2 Description of Known Hazards and Evaluation of Risks $\ldots \ldots \ldots 26$

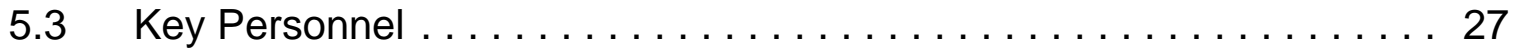

5.4 Delineation of Work Area $\ldots \ldots \ldots \ldots \ldots \ldots \ldots \ldots \ldots \ldots \ldots \ldots \ldots$

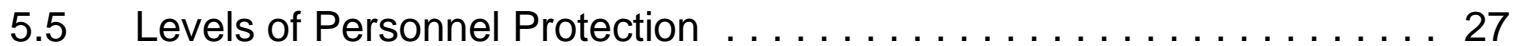

5.6 Procedures for Site Access Control . . . . . . . . . . . . . . 28

5.7 Decontamination Procedures for Personnel and Equipment . . . . . 28

5.8 Site Emergency Procedures $\ldots \ldots \ldots \ldots \ldots \ldots \ldots \ldots \ldots \ldots \ldots$

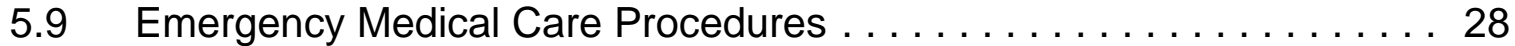

5.10 Environmental Field Monitoring Program $\ldots \ldots \ldots \ldots \ldots \ldots \ldots 28$

5.11 Routine and Special Training Requirements for Responders . . . . . . 28

5.12 Procedures for Protecting Workers from Weather-Related

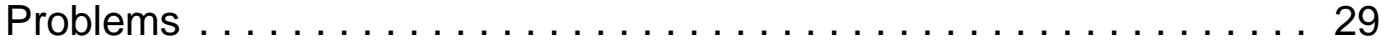

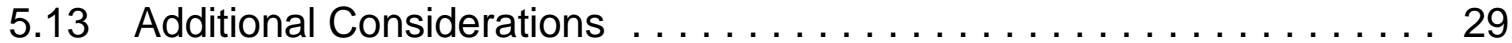

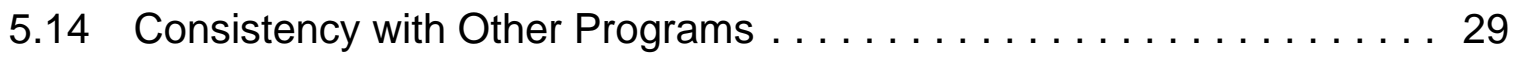

6.0 COMMUNITY RELATIONS PLAN $\ldots \ldots \ldots \ldots \ldots \ldots \ldots \ldots \ldots \ldots \ldots$

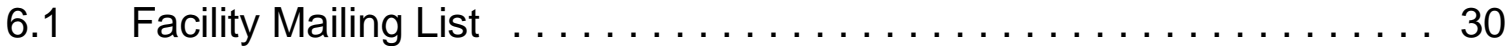

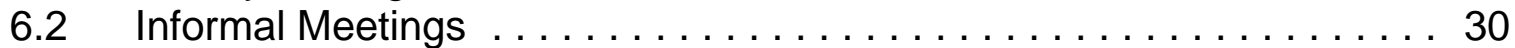

6.3 News Releases, Fact Sheets, Approved RFI Work Plans, RFI Reports, Special Permit Conditions Reports, and Quarterly

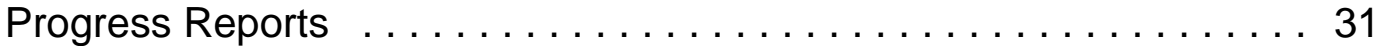

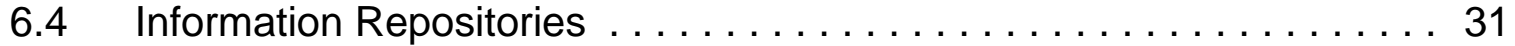

6.5 Updates of Materials in the Information Repositories and

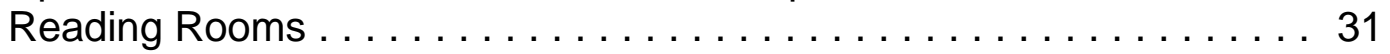

6.6 Quarterly Technical Progress Reports $\ldots \ldots \ldots \ldots \ldots \ldots \ldots \ldots . \ldots \ldots$

$6.7 \quad$ Immediate Notifications $\ldots \ldots \ldots \ldots \ldots \ldots \ldots \ldots \ldots \ldots \ldots \ldots \ldots$

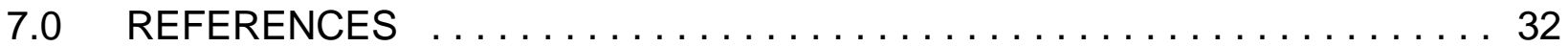




\section{ACRONYMS}

\begin{tabular}{|c|c|}
\hline $\mathrm{AOC}$ & Area of Concern \\
\hline ASTM & American Society for Testing and Materials \\
\hline CAO & Carlsbad Area Office \\
\hline CAP & Corrective Action Program \\
\hline CFR & Code of Federal Regulations \\
\hline $\mathrm{Cl}$ & Cognizant Individual \\
\hline CLP & Contract Laboratory Program \\
\hline CMI & Corrective Measure Implementation \\
\hline CMS & Corrective Measures Study \\
\hline $\mathrm{COC}$ & Chain of Custody \\
\hline DCQAP & Data Collection Quality Assurance Plan \\
\hline DMP & Data Management Plan \\
\hline DOE & U.S. Department of Energy \\
\hline DQO & Data Quality Objective \\
\hline DSP & Duval Sulphur \& Potash Company \\
\hline EC\&S & Environmental Compliance and Support \\
\hline EM & Environmental Monitoring \\
\hline EPA & U.S. Environmental Protection Agency \\
\hline ES & Exhaust Shaft \\
\hline$E S \& H$ & Environmental Safety and Health \\
\hline Expl. & Exploration \\
\hline FWP & Facility Work Plan \\
\hline GIS & Geographic Information System \\
\hline HSWA & Hazardous and Solid Waste Amendments \\
\hline IDM & Investigative-Derived Material \\
\hline $\mathrm{IH}$ & Industrial Hygiene \\
\hline IM & Interim Measure \\
\hline IMC & International Minerals \& Chemical Corporation \\
\hline LWA & Land Withdrawal Act \\
\hline MRL & Method Reporting Limit \\
\hline MS & Matrix Spike \\
\hline MSD & Matrix Spike Duplicate \\
\hline MSHA & Mine Safety and Health Administration \\
\hline & Not Applicable \\
\hline
\end{tabular}

$\mathrm{NIOSH} \quad$ National Institute for Occupational Safety and Health 


\begin{tabular}{|c|c|}
\hline NMAC & New Mexico Administrative Code \\
\hline NMED & New Mexico Environment Department \\
\hline OSHA & Occupational Safety and Health Administration \\
\hline OSWER & Office of Solid Waste and Emergency Response \\
\hline PARCC & Precision, Accuracy, Representativeness, Completeness, Comparability \\
\hline PPE & Personal Protective Equipment \\
\hline QA & Quality Assurance \\
\hline QAPjP & Quality Assurance Project Plan \\
\hline QC & Quality Control \\
\hline Q\&RA & Quality and Regulatory Assurance \\
\hline RCRA & Resource Conservation and Recovery Act \\
\hline RFA & RCRA Facility Assessment \\
\hline RFI & RCRA Facility Investigation \\
\hline RIDS & Record Inventory and Disposition Schedule \\
\hline RPD & Relative Percent Difference \\
\hline SARM & Standard Analytical Reference Material \\
\hline SOP & Standard Operating Procedure \\
\hline SOW & Statement of Work \\
\hline SWMU & Solid Waste Management Unit \\
\hline VRA & Voluntary Release Assessment \\
\hline WH & Waste Handling \\
\hline WHS & Waste Handling Shaft \\
\hline WID & Waste Isolation Division \\
\hline WLWA & WIPP Land Withdrawal Area \\
\hline WIPP & Waste Isolation Pilot Plant \\
\hline WP & Work Plan \\
\hline
\end{tabular}




\section{DEFINITIONS}

Area of Concern $(A O C)^{1}$ - Any discernable unit or area which, in the opinion of the NMED Secretary, may have received solid or hazardous waste or waste containing hazardous constituents at any time.

Hazardous Constituent ${ }^{1}$ - Any constituent identified in 20 NMAC 4.1.200 (incorporating 40 CFR §261 Appendix VIII), any constituent identified in 20 NMAC 4.1.500 (incorporating 40 CFR \$264 Appendix IX), any constituent identified in a hazardous waste listed in 20 NMAC 4.1.200 (incorporating 40 CFR §261 Subpart D), or any constituent identified in a toxicity characteristic waste in 20 NMAC 4.1.200 (incorporating 40 CFR §264.24, Table 1).

Hazardous Waste ${ }^{1}$ - A solid waste, or combination of solid wastes, which because of its quantity, concentration, or physical, chemical, or infectious characteristics may cause, or notably contribute to, an increase in mortality or an increase in serious irreversible, or incapacitating reversible, illness; or pose a substantial present or potential hazard to human health or the environment when improperly treated, stored, transported, or disposed of, or otherwise managed.

HSWA $^{1}$ - The 1984 Hazardous and Solid Waste Amendments to RCRA

LWA - WIPP Land Withdrawal Act (Public Law 102-579) transferred the responsibility for the management of the WIPP Land Withdrawal Area (WLWA) from the United States Secretary of the Interior to the United States Secretary of Energy. These lands "are withdrawn from all forms of entry, appropriation, and disposal under the public land laws" and are reserved for the use of the Secretary of Energy "for the construction, experimentation, operation, repair and maintenance, disposal, shutdown, monitoring, decommissioning, and other activities, associated with the purposes of WIPP."

RCRA $^{1}$ - The Resource Conservation and Recovery Act of 1980 as amended by HSWA in 1984.

Release $^{1}$ - Any spilling, leaking, pouring, emitting, emptying, discharging, injecting, pumping, escaping, leaching, dumping, or disposing of hazardous wastes (including hazardous constituents) into the environment (including the abandonment or discarding of barrels, containers, and other closed receptacles containing hazardous wastes or hazardous constituents).

Solid Waste Management ${ }^{1}$ - The systematic administration of activities which provide for the collection, source separation, storage, transportation, transfer, processing, treatment, and disposal of solid waste.

\footnotetext{
${ }^{1}$ These definitions were extracted directly from the October 27, 1999 Waste Isolation Pilot Plant Hazardous Waste Permit.
} 
Solid Waste Management Unit (SWMU) ${ }^{1}$ - Any discernible unit at which solid wastes have been placed at any time, irrespective of whether the unit was intended for the management of solid or hazardous waste. Such units include any area at a facility at which solid wastes have been routinely and systematically released. The definition includes regulated units (i.e., landfills, surface impoundments, waste piles, and land treatment units), but does not include passive leakage or one-time spills from production areas and units in which wastes have not been managed (e.g., product storage areas).

WLWA - WIPP Land Withdrawal Area is the 16 section Federal land area under the jurisdiction of the DOE containing and surrounding the WIPP facility. This area is located in Eddy County, New Mexico, approximately 26 miles east of Carlsbad, New Mexico. 


\section{$1.0 \quad$ INTRODUCTION}

This Facility Work Plan (FWP) has been prepared as required by Module VII, Section VII.M.1 of the Waste Isolation Pilot Plant (WIPP) Hazardous Waste Permit, NM4890139088-TSDF (the Permit); (NMED, 1999a). This work plan describes the programmatic facility-wide approach to future investigations at Solid Waste Management Units (SWMUs) and Areas of Concern (AOCs) specified in the Permit. This FWP addresses the current Permit requirements. It uses the results of previous investigations performed at WIPP and expands the investigations as required by the Permit. As an alternative to the Resource Conservation and Recovery Act (RCRA) Facility Investigation (RFI) specified in Module VII of the Permit, current New Mexico Environment Department (NMED) guidance identifies an Accelerated Corrective Action Approach (ACAA) that may be used for any SWMU or AOC (NMED, 1998). This accelerated approach is used to replace the standard RFI Work Plan and Report sequence with a more flexible decision-making approach. The ACAA process allows a Facility to exit the schedule of compliance contained in the Facility's Hazardous and Solid Waste Amendments (HSWA) permit module and proceed on an accelerated time frame. Thus, the ACAA process can be entered either before or after an RFI Work Plan. According to NMED's guidance, a facility can prepare an RFI Work Plan or Sampling and Analysis Plan (SAP) for any SWMU or AOC (NMED, 1998). Based on this guidance, a SAP constitutes an acceptable alternative to the RFI Work Plan specified in the Permit. The scope of work for the RFI Work Plan or SAP is being developed by the Permittees. The final content of the RFI Work Plan or SAP will be coordinated with the NMED for submittal on May 24, 2000. Specific project-related planning information will be included in the RFI Work Plan or SAP.

The SWMU program at WIPP began in 1994 under U.S. Environmental Protection Agency (EPA) regulatory authority. NMED subsequently received regulatory authority from EPA. A Phase I RFI was completed at WIPP as part of a Voluntary Release Assessment (VRA). The risk-based decision criteria recommended by EPA for the VRA were contained in a proposed Corrective Action rule for SWMUs (EPA, 1990). EPA Region VI has issued new risk-based screening criteria applicable to the WIPP SWMUs and AOCs.

Based on the results of the VRA and current EPA risk-based screening criteria for industrial facilities, the Permittees envision that completion of the RFI or implementation of the SAP will demonstrate that there is no need for corrective action at any SWMU or AOC. The Permittees believe that the results of the field investigations will lead to a request for No Further Action (NFA) for all SWMUs and AOCs specified in the permit. Approval of the NFA request by NMED will allow the Permittees to request a permit modification to exit the RFI/Corrective Measures process, and remove the SWMUs and AOCs from the Permit.

\section{$1.1 \quad$ Facility Background}

The Westinghouse Government Environmental Services Company, LLC, Waste Isolation Division (WID) is the co-operator of the WIPP hazardous waste facility. For the 
purposes of this FWP, references to WIPP personnel include both DOE and co-operator personnel. The WIPP facility consists of surface buildings and structures, an underground network of subsurface excavated openings, and vertical shafts, which connect the surface and subsurface areas. Waste, equipment, and personnel enter the underground facility through designated shafts.

The underground hazardous waste disposal units (HWDUs) defined as waste panels, are located 2150 feet (655 meters) below ground surface, in the WIPP underground. The waste panels consist of seven rooms and two access drifts each. Each room is approximately 300 feet (91 meters) long, 33 feet (10 meters) wide, and 13 feet (4 meters) high. Access drifts connect the rooms and have the same cross section. The hazardous waste management units are not addressed within this FWP.

\subsection{SWMUs and AOCs Identified in the Permit}

The Permit identifies 15 SWMUs requiring an RFI, 3 SWMUs not requiring an RFI (the hazardous waste management units), and 8 AOCs in the 16 section WIPP Land Withdrawal Area (WLWA). The WIPP Land Withdrawal Act (Public Law 102-579) created the WLWA in October 1992. This Act transferred the responsibility for the management of the WLWA from the Secretary of the Interior to the Secretary of Energy. In accordance with sections 3(a)(1) and (3) of the Act, these lands ". . . are withdrawn from all forms of entry, appropriation, and disposal under the public land laws . . . " and are reserved for the use of the Secretary of Energy ". . . for the construction, experimentation, operation, repair and maintenance, disposal, shutdown, monitoring, decommissioning, and other activities, associated with the purposes of WIPP as set forth in Section 213 of the Department of Energy National Security and Military Applications of Nuclear Energy Act of 1980 (Public Law 96-164; 93 Statute 1259, 1265) and this Act." Some of the SWMUs and AOCs were identified in the original RCRA Part B Permit Application for the facility (Revision 0, DOE/WIPP 91-005), and were included in a RCRA Facility Assessment (RFA) performed by the New Mexico Environment Department (NMED) (NMED/DOE/AIP 94/1, 1994). The 15 SWMUs and 8 AOCs identified in the Permit are associated with: (1) natural resource exploration activities prior to the development of the WIPP, or (2) early WIPP mineral assessment and geological studies to support the development of the facility, or (3) facility construction. More information on each SWMU and AOC can be found in Assessment of Solid Waste Management Units at the Waste Isolation Pilot Plant (NMED, 1994), the WIPP RCRA Facility Assessment (RFA), Final Voluntary Release Assessment/Corrective Action Report (DOE, 1996), Supplemental Information Requested by the New Mexico Environment Department for Solid Waste Management Units (DOE, 1997a), and Technical Support Document, Exclusion/Inclusion of Solid Waste Management Units and Areas of Concern (NMED, 1999).

\subsubsection{SWMU Descriptions}

The 15 SWMUs included in the Permit that require an RFI are:

- $\quad$ SWMU 001g (H-14/P-1 Mud Pits) 


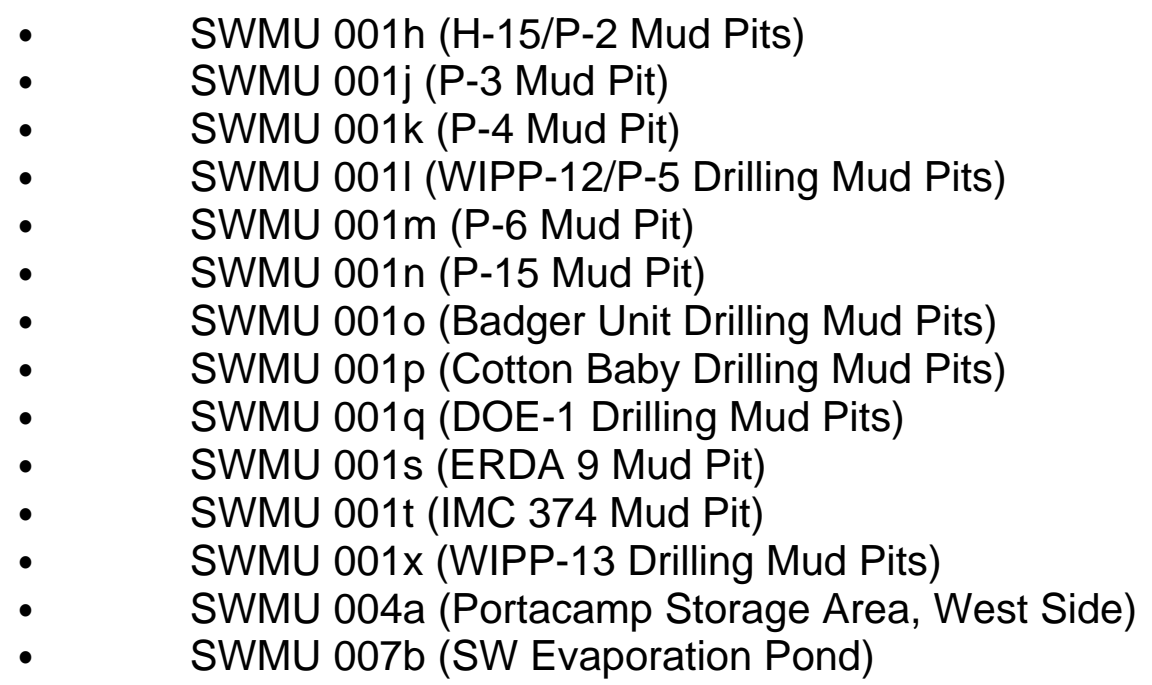

Brief summaries of each SWMU are presented below.

\subsubsection{Areas of Concern}

The eight AOCs included in the Permit are:

$\begin{array}{ll}- & \text { AOC 001r (D-123 Mud Pit) } \\ : & \text { AOC 001u (IMC-376 Mud Pit) } \\ \text { - } & \text { AOC 001v (IMC-456 Mud Pit) } \\ \text { - } & \text { AOC 001w (IMC-457 Mud Pit) } \\ \text { - } & \text { AOC 001ac (DSP-207 Mud Pit) } \\ \text { - } & \text { AOC 001ae (IMC-377 Mud Pit) } \\ & \text { AOC 010b (Waste Handling Shaft Sump) }\end{array}$

\subsection{Work Plan Organization}

As required by the Permit, this FWP considers the following primary topics: Section 2.0 presents the project management plan, Section 3.0 presents the data collection quality assurance plan, Section 4.0 presents the data management plan, Section 5.0 presents the site safety and health plan, and Section 6.0 presents the community relations plan. Finally, references for this FWP are presented in Section 7.0. The organization of this FWP follows the requirements of Module VII of the Permit.

\subsection{PROJECT MANAGEMENT PLAN}

This section of the FWP provides a generalized overview of the project management plan for conducting future RFI Work Plan or SAP activities. As such, this Project Management Plan responds to the requirements in Sections VII.,M and VII.U.3.j of the Permit. The technical approach, schedules, budget, key personnel, key personnel qualifications, and the overall management approach for the RFI are described in the following subsections. 


\subsection{Technical Approach, Schedules, Budget, and Key Project Personnel}

\subsubsection{Technical Approach}

The overall program objectives for the RFI Work Plan or SAP at WIPP include:

- $\quad$ Complete the RFI Work Plan or SAP, as necessary, to characterize the nature, rate, and extent of hazardous constituents sufficiently to make corrective action decisions (including NFA) for SWMUs and AOCs

- $\quad$ Negotiate, plan, and implement future investigations, based on existing site information, regulatory requirements, and required decisions, utilizing the U.S. Environmental Protection Agency (EPA) RFI planning documents and data quality objectives (DQO) process

- $\quad$ Perform needed investigations in a cost-effective manner

- $\quad$ Comply with the Permit requirements for the SWMUs/AOCs

EPA guidance states, "the scope and complexity of remedial investigations will depend on the nature and extent of the contamination, whether the releases have migrated beyond the facility boundary, the amount of existing information on the site, the likely risk at the site, and other pertinent factors" (EPA, 1990). Because a large body of analytical, technical, and risk information exists for these SWMUs/AOCs, these data will be considered for planning and negotiating specific goals and activities.

Because of the quantity of information obtained during the Voluntary Release Assessment (VRA) program at the WIPP, the first phase of the RFI has already been performed. The technical approach for subsequent investigations (i.e., the RFI Work Plan or SAP) will involve further investigation of SWMUs where releases of hazardous constituents were identified during the VRA, and initial investigations at AOCs to evaluate potential releases.

The information collected to date will be incorporated into the RFI Work Plan or SAP as suggested by EPA (1994a, 1989a). Data on site conditions, previous release sampling and analysis results, and site-specific risk evaluations will form the basis for future investigations.

Program implementation will also incorporate EPA's DQO process to tailor data gathering strategies for the purpose of making corrective action decisions (EPA, 1987, 1993, 1994b, 1998a). The DQO process will be used to ensure that environmental data are adequate, scientifically valid, defensible, and of an appropriate level of quality, given the intended use for the data in corrective action decision-making. DQO specifications will be defined in the RFI Work Plan or SAP. 
If additional risk evaluations are required for the SWMUs/AOCs, appropriate EPA guidance documents will be used during the evaluations (EPA, 1989b, 1992, 1996, 1997a, 1998b).

\subsubsection{Schedules}

Two primary dates are contained in the Permit Corrective Action Schedule of Compliance. The first date is for this FWP. This FWP will be submitted to NMED no later than February 24, 2000 (90 days after the effective date of the RCRA Permit). Annual reviews and updates to the FWP will be completed as necessary. The second Permit date is for the RFI Work Plan, which will be completed no later than May 24, 2000 (180 days after the effective date of the RCRA Permit). Other permit-required dates are tied to specific occurrences or agency approvals.

Provision VII.I.1 of the Permit requires the submittal of quarterly progress reports to NMED to document implemented RFI Work Plan or SAP activities. In accordance with this provision, the Permittees will initiate submittal of quarterly reports no later than 90 days after beginning each RFI Work Plan or SAP activity, and will continue submittal until each activity is complete. Specific deliverables and their submittal schedules will be defined in the RFI Work Plan or SAP.

\subsubsection{Budget}

The final scope of the RFI Work Plan or SAP is currently being defined. Budget allocations will be made based on a defined scope of work approved by NMED, and on specific, well-defined program decisions. Specific funding allocated to completing the RFI activities or implementing the SAP will be included in the RFI Work Plan or SAP.

\subsubsection{Key Project Personnel}

A number of WIPP personnel will be involved in fulfilling the RFI Work Plan or SAP. The SWMU Project Manager from Environmental Compliance (EC) will be responsible for coordinating activities related to the RFI Work Plan or SAP. The SWMU Project Manager will marshal and monitor needed resources for the program and serve as liaison between other cognizant organizations. The SWMU Project Manager will report to the DOE through the Environmental Safety and Health (ES\&H) manager.

Other organizations that may be involved in implementing the RFI Work Plan or SAP include: the Sampling Team, Information Resource Management (for electronic data management and processing support), Industrial Safety and Hygiene (for health and safety issues), Public Affairs (for community relations support), Quality Assurance, RCRA Permitting, and subcontractors. The actual involvement of these organizations and their direct responsibilities will be solicited as needed by the SWMU Project Manager. Responsible organizations and individuals will be specified as part of the RFI Work Plan or SAP. 


\subsection{Key Project Personnel Qualifications}

As described in Section 2.1.3, number of WIPP personnel will be involved in fulfilling the requirements of the RFI Work Plan or SAP. As the scope of the RFI Work Plan or SAP is finalized, the SWMU project Manager will define the necessary qualifications of individuals who will be responsible for implementing RFI activities or the SAP. The selected individuals and their required qualifications will be identified in the RFI Work Plan or SAP.

Qualifications for these responsible individuals will include necessary training and experience for the RFI Work Plan or SAP tasks in their area of responsibility.

\subsection{Overall Management Approach to the RFI}

The RFI Work Plan or SAP activities will be managed by qualified WIPP personnel using cost and schedule control measures, and adhering to strict quality assurance and quality control (QA/QC) criteria. Cost control will benefit WIPP and the taxpayers by ensuring that funds are expended in the most cost-effective manner. Schedule control will be achieved by monitoring planned versus actual task duration, which will enable the Permittees to monitor progress and ensure that deliverables specified in the Permit are submitted to NMED in a timely manner. Appropriate QA/QC procedures employed during the process will ensure that RFI Work Plan or SAP objectives are met.

\subsection{DATA COLLECTION/QUALITY ASSURANCE PLAN}

This section of the FWP provides a generalized Data Collection Quality Assurance Plan (DCQAP) for data collection activities performed as part of RFI Work Plan or SAP activities at WIPP SWMUs and AOCs. As such, this DCQAP responds to the requirements specified in Sections VII.M and VII.U.3.f of the Permit. This DCQAP also identifies generalized procedures for sample collection and analysis as part of RFI Work Plan or SAP activities, as documented in existing WIPP plans and procedures. This DCQAP will serve as the basis for the development and preparation of the RFI Work Plan or SAP. The RFI Work Plan or SAP will supplement this DCQAP by further defining the specific procedures and requirements for each sampling activity specified in Section VII.U.3.f of the Permit. Together with the RFI Work Plan or SAP, implementation of this DCQAP will produce a complete, detailed, and ongoing record of the data collection and QA activities.

The objectives of the DCQAP are as follows:

- $\quad$ Provide a consistent framework for generating analytical data throughout the RFI Work Plan or SAP implementation.

- $\quad$ Address the quality of analytical systems used to perform data collection.

- Identify procedures that demonstrate that the sampling, analytical, and data reporting systems are achieving program objectives. 
Set forth record-keeping procedures commensurate with project data uses.

Provide for the generation and documentation of data of known and acceptable quality.

Additional specific data collection quality assurance information will be included in the RFI Work Plan or SAP as the details are finalized.

\subsection{Data Collection Quality Assurance Strategy}

Decision objectives and data uses for Work Plan or SAP data collection activities will be defined in the RFI Work Plan or SAP. In general, decisions for the RFI Work Plan or SAP will be based on risk. The NMED and the Permittees are currently evaluating the appropriate screening criteria for use in risk evaluations at the SWMUs and AOCs, in accordance with applicable EPA guidance. Investigation activities will be designed to identify and characterize releases of hazardous constituents from SWMUs/AOCs. Additional decision objectives for data collection activities will be the effective and costefficient implementation of the RFI Work Plan or SAP. The RFI Work Plan or SAP will include decision diagrams that display how data will be applied to meet RFI Work Plan or SAP objectives and make specific program decisions.

\subsubsection{Intended Data Uses}

The general data use categories identified for each data collection activity under the Work Plan or SAP will be consistent with EPA guidance regarding DQOs (EPA, 1993, 1994b). DQOs are qualitative and quantitative statements that specify the quality of the data required to support decisions made under the RFI Work Plan or SAP, and are based on the end uses of the data to be collected. As such, different data uses may require different levels of data quality. The DQOs will be defined in the RFI Work Plan or SAP.

New data collection activities for the RFI Work Plan or SAP will include the generation of definitive data for the AOCs and SWMUs. EPA defines definitive data to be:

"Generated using rigorous analytical methods and QA protocols in environmental analytical laboratories. Definitive data provide reliable, well-documented identification, quantification, and confirmation of target analytes. Definitive data will generally be required for decisions regarding risk and/or the implementation of corrective measures. The results generated from definitive analyses must be scientifically defensible data that can prove or disprove a hypothesis with no additional information beyond that provided in the data package."

Definitive data will be generated to assess the nature, rate and extent of hazardous constituents in SWMUs and AOCs, and whether these constituents have been released to the surrounding media at concentrations above decision criteria. The necessary level of precision and accuracy for the decision criteria will be defined in the RFI Work Plan or SAP and will be consistent with the sampling and analysis methods selected for the investigations. 


\subsubsection{Methods and Procedures to Assess Precision, Accuracy, and Completeness}

Data quality objectives for the definitive data collected in support of the RFI Work Plan or SAP are defined in this section. Data quality is defined in terms of: precision, accuracy, and completeness.

\section{Precision and Accuracy}

Precision is the measure of mutual agreement among separate measurements of the same property, usually under prescribed similar conditions. Precision describes the effects random errors have on analytical measurements. Precision is typically measured in a system by the relative percent difference (RPD) between duplicate measurements.

Accuracy is the measure of the agreement of a value with an accepted reference. Accuracy is used to estimate the effect of systematic errors, or biases, on analytical measurements required to make programmatic decisions. Accuracy is typically measured in a system by calculating the percent recovery or percent difference from an analytical standard. Field and laboratory blank data can also reveal systematic errors and biases.

The precision and accuracy of a data set are generally functions of the analytical method and sample matrix. Although the sample analysis methods and the procedures to be used to assess the precision and accuracy of the measurement data have not been finalized, the Permittees will use the appropriate methods from SW-846 (EPA, 1997b) for analysis of constituents defined in the TSD (NMED, 1999b). Additional details for these methods will be defined in the RFI Work Plan or SAP.

Precision and accuracy objectives for definitive sample analyses to be performed in support of the RFI Work Plan or SAP activities will be documented in laboratory SOPS to be provided by the subcontractor laboratory for the analytical methods used for specific projects. The laboratory's analytical method SOPs will be based on the standard EPA methods specified in the RFI Work Plan or SAP. The precision and accuracy achieved by the laboratory will be consistent with the requirements established by the laboratory method startup protocol, as well as applicable EPA method requirements for inorganic analyses. The overall precision and accuracy of the reported results will be evaluated when decisions are made concerning the achievement of performance standards for the RFI Work Plan or SAP activities. Details on these objectives will be included in the RFI Work Plan or SAP.

\section{$\underline{\text { Completeness }}$}

Completeness is the amount of valid data obtained from a measurement system compared to the amount that was expected and needed to be obtained to meet the project data goals. 
The data completeness goal for this program is 85 percent. This completeness goal is considered adequate to meet the potential data uses for the RFI Work Plan or SAP, based on prior consideration of QA/QC parameters, the sampling design plans, and the envisioned data collection activities. Data completeness will be represented as the amount of valid data obtained versus the amount of data expected or planned for a given RFI Work Plan or SAP activity. Data that are rejected through data validation will be counted against completeness goals. The SWMU Project Manager or designated representative will perform the evaluation of completeness.

\subsubsection{Schedule and Information to be Provided in Quality Assurance Reports}

QA/QC assessment and review will be performed by the Permittees during the RFI Work Plan or SAP activities. Assessment, review, and response actions will be performed in accordance with the established WIPP QA program as documented in the WID Quality Assurance Program Description (WP 13-1) and the Quality Assurance Project Plan for WIPP Site Effluent and Hazardous Materials Sampling (WP 02-EC.05). Team members participating in RFI Work Plan or SAP activities are collectively responsible for assessment activities, and have authority to implement corrective action or stop work depending on the situation. Examples of project assessment activities that could be applied during the RFI in accordance with established facility QA protocols are listed below:

- $\quad$ Periodic assessment of measurement data (accuracy, precision, and completeness)

- $\quad$ Performance audits

- $\quad$ Systems audits of field and laboratory operations

- Identification of quality assurance problems and resolutions (corrective actions)

Quality control and quality assurance data will be included in quality assurance reports. As a minimum, a quality assurance report will be prepared and distributed to summarize both the field activities performed and the results for collected data at the conclusion of the field investigation. This report will include the following information, as appropriate:

- Data validation reports summarizing the validation process used and specific comments pertaining to a sample or group of samples

- $\quad$ Summaries of accuracy, precision, and completeness for the field and laboratory data

- $\quad$ Results of performance and systems audits

- Identification and resolution of quality assurance problems 
Additional details on this report will be included in the RFI Work Plan or SAP.

\subsection{Sampling and Field Measurements}

The design of the sampling program is critical to the production of representative data. EPA identifies four sampling strategies in Chapter 9 of SW-846 (EPA, 1997b). The use of a sampling strategy is based on the prior knowledge of the site and specific material being investigated. The sampling strategy envisioned for the RFI Work Plan or SAP is authoritative sampling.

Authoritative sampling is used when there is specific knowledge of the medium to be sampled and sources of chemical constituents. Samples of the medium are collected based on the knowledge of the likely concentration of chemical constituents, without regard to randomization. Factors including history of the area, physical and chemical behavior of contaminants, and physical system effects on contaminant fate and transport are considered when selecting sample sites.

Specific sampling approaches based on the above technique will be defined in the RFI Work Plan or SAP. The following information on sampling program design will be included:

- $\quad$ Selecting appropriate sampling and field measurements locations

- Defining a statistically sufficient number of sampling and field measurement sites

- Defining conditions under which sampling or field measurements will be conducted

- $\quad$ Defining which parameters are to be measured and where

- $\quad$ Selecting the frequency of sampling and length of sampling period

- $\quad$ Selecting the types of sample and number of samples to be collected

- $\quad$ Delineating procedures designed to prevent contamination of sampling or field measurements equipment and cross contamination between sampling points

- $\quad$ Documenting field sampling operations and procedures

- $\quad$ Selecting appropriate sample containers

- $\quad$ Preserving samples

- $\quad$ Controlling chain-of-custody (COC)

- Disposing of contaminated materials generated by investigation activities 
General sampling guidelines for the RFI Work Plan or SAP are summarized and/or referenced below. Sampling under the RFI Work Plan or SAP will be performed in accordance with written documentation including a quality assurance project plan and a written sampling plan. These documents will either be revisions of current WIPP plans or new plans developed specifically for the RFI Work Plan or SAP (see, WP 02-EC.05, Quality Assurance Project Plan for WIPP Site Effluent and Hazardous Material Sampling, for an example).

\subsubsection{Selecting Sampling and Field Measurements Locations}

The only field measurements that will be included in the RFI Work Plan or SAP are soil samples and documentation of sample locations. Appropriate sampling locations for the RFI Work Plan or SAP will be determined based on previous sampling and analysis results from the VRA. Sample locations will be selected to allow the extent of contamination to be more carefully defined. Sample depths will be consistent with sample depths used for the VRA. The RFI Work Plan or SAP will define the selection process for field samples.

\subsubsection{Number of Sampling and Field Measurement Sites}

Samples will be collected at each SWMU as necessary to determine the extent of contamination and at each AOCs to evaluate if a release has occurred. Authoritative samples will be collected at every SWMU where a release has occurred. In addition, samples will be collected at six mudpit AOCs. The sampling approach will provide a statistically significant number of sampling and field measurement sites in accordance with EPA methods. Details on the number and locations of planned samples will be included in the RFI Work Plan or SAP.

\subsubsection{Sampling Conditions}

Only soil samples will be collected under the RFI Work Plan or SAP. The only additional field measurements anticipated are defining the locations of the soil samples (e.g., horizontal and vertical location). In general, only adverse weather conditions (i.e., rain, high winds) will restrict soil sample collection at the SWMUs and AOCs.

\subsubsection{Measurement Parameters}

The Permittees envision that the measurement parameters will include: sample location, sample depth, four inorganic constituent concentration (i.e., barium, chromium, lead, and nickel) and one organic constituent concentration (i.e., methanol). The inorganic and organic constituents selected for each SWMU or AOC will be based on the NMED TSD (NMED, 1999b). Additional detail on the measurement parameters will be included in the RFI Work Plan or SAP. 


\subsubsection{Frequency of Sampling, and Length of Sampling Period}

Only one round of sampling is anticipated for each SWMU and AOC. In addition, it is anticipated that the sampling will be completed in 20 workdays. The length of each sampling day will encompass a single work shift for the sampling team. The RFI Work Plan will establish the schedule for sampling at the SWMUs and AOCs.

\subsubsection{Types and Number of Samples}

It is anticipated that soil investigative grab samples and QC samples (i.e., rinseate) will be collected under the RFI Work Plan or SAP. In addition, it is anticipated that three to five sampling locations will be identified in and around each SWMU or AOC sampled. No composite sampling is planned. The RFI Work Plan or SAP will define the final sampling approach, including the type, number, and locations of samples for each SWMU and AOC.

\subsubsection{Procedures to Prevent Contamination}

Field sampling procedures to prevent contamination of sampling or field measurements equipment and cross contamination between sampling points include using dedicated sampling equipment and decontaminating the equipment after collecting each sample. The procedures used for the RFI Work Plan or SAP will be consistent with sampling procedures recommended by the EPA. Current procedures used at the WIPP site are documented in the Quality Assurance Project Plan for WIPP Site Effluent and Hazardous Materials Sampling (WP 02-EC.05) and WIPP Site Effluent and Hazardous Materials Sampling Plan (WP 02-EC.06). Modifications to these documents may be appropriate for the RFI Work Plan or SAP. Additional detail regarding procedures to prevent contamination will be included in the RFI Work Plan or SAP.

\subsubsection{Sampling Operations and Procedures}

Field documentation protocols for sampling operations and procedures included in the RFI Work Plan or SAP will be consistent with EPA guidance. Current procedures used at the WIPP site are documented in the Quality Assurance Project Plan for WIPP Site Effluent and Hazardous Materials Sampling (WP 02-EC.05) and WIPP Site Effluent and Hazardous Materials Sampling Plan (WP 02-EC.06). Modifications to these documents may be appropriate for the RFI Work Plan or SAP to address the following:

- $\quad$ Sample collection procedures

- $\quad$ Sampling equipment decontamination

- $\quad$ Field documentation practices

- $\quad$ Sample chain of custody

- $\quad$ Sample containers, preservation, and holding times

- $\quad$ Sample classification, handling, and shipping 
Specific procedures and requirements for RFI Work Plan or SAP activities included in applicable existing WIPP sampling plans and manuals will be extracted and included as necessary in the RFI Work Plan or SAP.

\subsubsection{Selecting Appropriate Sampling Containers}

It is anticipated that polyethylene containers will be used for soil samples that will be analyzed for inorganic constituents. Glass containers will be used for soil samples that will be analyzed for organic constituents. Procedures for selecting appropriate sampling containers will be consistent with EPA guidance. Current procedures used at the WIPP site are documented in the Quality Assurance Project Plan for WIPP Site Effluent and Hazardous Materials Sampling (WP 02-EC.05) and WIPP Site Effluent and Hazardous Materials Sampling Plan (WP 02-EC.06). The analytical methods and subcontractor laboratory SOPs for the sample analyses will also be used to select the appropriate sampling containers. Additional detail regarding selecting appropriate sampling containers will be included in the RFI Work Plan or SAP.

\subsubsection{Preserving Samples}

For soil samples, no chemical preservatives are anticipated. Samples will be cooled to four degrees centigrade after collection and during shipping and storage. Aqueous QC samples will be preserved with nitric acid. Procedures for preserving samples will be consistent with EPA guidance. Current procedures used at the WIPP site are documented in the Quality Assurance Project Plan for WIPP Site Effluent and Hazardous Materials Sampling (WP 02-EC.05) and WIPP Site Effluent and Hazardous Materials Sampling Plan (WP 02-EC.06). The analytical methods and subcontractor laboratory SOPs for the sample analyses will also be used to define any needed preservatives for the samples. Additional detail regarding preserving samples will be included in the RFI Work Plan or SAP.

\subsubsection{Controlling Chain-of-Custody}

Procedures for controlling $\mathrm{COC}$ will be consistent with EPA guidance. Current procedures used at the WIPP site are documented in the Quality Assurance Project Plan for WIPP Site Effluent and Hazardous Materials Sampling (WP 02-EC.05) and WIPP Site Effluent and Hazardous Materials Sampling Plan (WP 02-EC.06). The subcontractor laboratory SOPs for the sample analyses will also be used to define procedures for controlling $\mathrm{COC}$ in the laboratory. Additional detail regarding controlling COC will be included in the RFI Work Plan or SAP.

\subsubsection{Disposing of Contaminated Materials Generated by Activities}

Based on historical sampling performed at the SWMUs, no contaminated materials (i.e., personal protective equipment, gloves, and decontamination water) are expected to be generated by the sampling activities. The SWMU contents are not classified as hazardous waste. If any contaminated materials are generated, they will be disposed of in a manner consistent with State and Federal regulations and facility procedures. 
Additional detail regarding disposing of contaminated materials will be included in the RFI Work Plan or SAP.

\subsection{Sample Analysis}

A subcontract analytical laboratory approved by the Permittees shall perform laboratory sample analyses in support of the RFI Work Plan or SAP. The subcontractor laboratory has not been selected. RFI Work Plan or SAP analytical programs will be consistent with EPA guidance. Sample analyses will be performed in accordance with the general requirements and procedures set forth in the Quality Assurance Project Plan for WIPP Site Effluent and Hazardous Materials Sampling (WP 02-EC.05). The specific target analytical parameters and the field and laboratory analytical methods to be applied during RFI Work Plan or SAP activities will be presented in the RFI Work Plan or SAP. Laboratory analytical methods for the RFI Work Plan or SAP will be based on standard reference methods from "Test Methods for Evaluating Solid Wastes" (EPA-SW-846), (EPA, 1997b). The subcontract laboratories shall develop and maintain a set of written instructions, or SOPs, for performance of the reference methods. Each method SOP cites the specific reference method on which it is based (e.g., EPA Method 6010B for inorganic compounds). The SOPs for the laboratory analytical methods to be applied in support of the RFI Work Plan or SAP activities shall be approved by the SWMU Project Manager for consistency with EPA method requirements and with program QA/QC objectives.

SOPS will be included in the RFI Work Plan or SAP and will include the following:

$\begin{array}{ll}\text { - } & \text { COC procedures } \\ \text { - } & \text { Sample storage procedures and holding times } \\ \text { - } & \text { Sample preparation methods } \\ \text { - } & \text { Canalytical procedures } \\ \text { - } & \text { Data reduction, validation and reporting } \\ & \text { Frequency of internal quality control checks and laboratory performance audits }\end{array}$

General SOP considerations for the RFI Work Plan or SAP are presented below.

\subsubsection{Chain-of-Custody Procedures}

The subcontractor laboratory for sample analysis has not been selected. Consequently, the WIPP and subcontractor laboratory SOPs for COC during sampling, shipment, handling, and analysis will be provided in the RFI Work Plan or SAP. COC procedures are included in Chapter 1 of EPA's SW-846 and are established to assure that samples are always under the control of responsible individuals who can maintain sample integrity. 


\subsubsection{Sample Storage Procedures and Holding Times}

Procedures for sample storage and holding times will be consistent with other procedures that have been established at the WIPP site, and with the analytical methods. The WIPP procedures are documented in the Quality Assurance Project Plan for WIPP Site Effluent and Hazardous Materials Sampling (WP 02-EC.05) and WIPP Site Effluent and Hazardous Materials Sampling Plan (WP 02-EC.06). The specific analytical methods and subcontractor laboratory for sample analysis have not been selected. Consequently, the subcontractor laboratory SOP for laboratory sample storage and holding times will be provided in the RFI Work Plan or SAP.

\subsubsection{Sample Preparation Methods}

The specific analytical methods and subcontractor laboratory for sample analysis have not been finalized. Consequently, the subcontractor laboratory SOP for laboratory sample preparation will be provided in the RFI Work Plan or SAP.

\subsubsection{Analytical Procedures}

The specific analytical methods and subcontractor laboratory for sample analysis have not been selected. Consequently, the subcontractor laboratory SOP for sample analysis will be provided in the RFI Work Plan or SAP.

\subsubsection{Calibration Procedures and Frequency}

The specific analytical methods and subcontractor laboratory for sample analysis have not been selected. Consequently, the subcontractor laboratory SOP for laboratory equipment calibration and frequency of calibration will be provided in the RFI Work Plan or SAP.

\subsubsection{Data Reduction, Validation, and Reporting}

The specific analytical methods and subcontractor laboratory for sample analysis have not been selected. Consequently, the procedures for data reduction, validation, and reporting have not been finalized. General considerations for data reduction, validation and reporting are provided below. Additional detail for these activities will be provided in the RFI Work Plan or SAP.

\subsubsection{Data Reduction}

Data reduction includes summarizing collected data and performing mathematical or statistical analyses. The selected subcontractor laboratory will reduce analytical data and provide the analytical data in an electronic format specified by the Permittees. The SWMU Project Manager or designee will amend the electronic data file to include the field-generated data and data qualifications. Analytical results and selected field measurements will be entered into the project database system described in Section 4.0 
of the FWP. Additional details for data reduction will be included in the RFI Work Plan or SAP.

\subsubsection{Data Validation}

Technical data, including field measurements and results of field sample analyses, will be reviewed and validated according to internal QA procedures to monitor the performance of each task. Laboratory analytical data will be validated according to method-specific SOPs and, where applicable, using methods consistent with the EPA Contract Laboratory Program National Functional Guidelines for Organics/Inorganics Data Review (EPA, 1994c, 1999a, 1999b, 1999c). Data collection and QA procedures for validating field measurements and laboratory data are described below. The RFI Work Plan or SAP will identify these requirements in greater detail.

\section{Field Measurement Data Validation Procedures}

Field measurement data validation procedures include reviewing the raw data and supporting documentation generated from field investigations. Validation of field data will be performed by the SWMU Project Manager or designated representative. Data validation will be performed to meet the project's intended data uses by checking the procedures used in the field and comparing the data to previous measurements. The following areas may be addressed during validation:

$\begin{array}{ll}\text { - } & \text { Documentation of field observations } \\ \text { - } & \text { Documentation of field procedures } \\ \text { - } & \text { Sampling methodology } \\ \text { - } & \text { Sample technical holding times and preservation } \\ \text { - } & \text { Instrument selection and use } \\ \text { - } & \text { Instrument calibration and standardization } \\ \text { - } & \text { Instrument preventative maintenance } \\ \text { - } & \text { Transcription and calculations } \\ \text { - } & \text { Field QC checks, if applicable } \\ \text { - } & \text { Field deviations } \\ \text { - } & \text { Field data completeness } \\ \text { - } & \text { Sampling limitations }\end{array}$

\section{Analytical Data Validation}

The program laboratory selected to perform definitive chemical analyses will participate in applicable EPA and/or other regulatory approval programs to assure that its analytical, QA/QC, and data reporting protocols are consistent with the project data quality objectives, and with general EPA data quality guidelines (EPA, 1994a). In general, definitive data produced by standard EPA methods for the determination of target analytes (e.g., EPA SW-846 methods) will be validated in a manner consistent with EPA Functional Guidelines for Evaluating Organic and Inorganic Analyses (EPA, 1994c, 1999a, 1999b, 1999c). Where EPA functional guidelines do not apply, the 
analytical data will be validated in accordance with the appropriate method SOPs and project control criteria. Features of the internal and external data validation programs for RFI Work Plan or SAP activities are summarized below.

- Internal Laboratory Data Validation: Under the direction of the laboratory QA manager, the laboratory will review analytical data to insure that results for investigative and QC samples meet EPA functional guidelines or methodspecified criteria. Laboratory review of analytical data will be performed in accordance with the Laboratory QA Plan and supporting SOPS and, as appropriate, will meet the general review requirements of Contract Laboratory Program (CLP) Statements of Work (SOWs) (EPA, 1994c, 1999a, 1999b, 1999c) and EPA guidance document SW-846 (EPA, 1997b). For target analytes that do not have QC criteria specified in EPA guidance documents, QC criteria will be based on laboratory method-specific data and will be defined in the RFI Work Plan or SAP.

- $\quad$ External Laboratory Data Validation Procedures: Definitive laboratory analytical data used for program decisions will be reviewed by the SWMU Project Manager or designated representative to independently validate the laboratory results. The level of effort required for data validation will depend on the project DQOs. Validation efforts may include review of the QC summary report submitted by the laboratory or may require review of the raw data provided by the laboratory. The level of validation effort will be specified in the RFI Work Plan or SAP. At a minimum, the reported analytical data will be reviewed for completeness and compliance with appropriate QC criteria. If problems with the analyses are found during the review that may affect the analytical results, the analytical data will undergo an additional raw data review and calculation check. The laboratory analytical data will be validated according to method-specific SOPs and/or EPA's Laboratory Data Validation Functional Guidelines for Organics/Inorganics Analyses (EPA, 1994c, 1999a, 1999b, 1999c). Where EPA QC limits are not available, laboratory-generated QC limits will be used.

Based on a comparison of the data with established QC limits, qualifiers will be applied to the data as necessary to document the utility of reported results. Data qualifiers and definitions, consistent with method-specific SOPs and/or EPA functional guidelines, will be used where appropriate in validation. Data qualifiers will be attached to the tabulated final analytical data to indicate the data quality relative to intended data use. The qualifiers will be attached to the data whenever they appear in hard copy or computerized form to assure that data users are aware of the quality and limitations of the data. Upon completion of data validation, validation summary reports will be placed with the original laboratory report packages in the project file.

Additional qualifiers may be added to the data at the discretion and approval of the SWMU Project Manager. When additional qualifiers are added to the data, a complete explanation of the qualifiers will accompany the data review. 


\subsubsection{Data Reporting}

Results of field sampling and analytical results will be included in the RFI Report. The data report will be prepared and distributed according to the requirements of the Permit. The report will describe both the field activities performed and the results for collected data. This report, to the extent possible, will include the following:

- $\quad$ Presentation of results

- $\quad$ Summaries of field data from field measurements

- $\quad$ Location of sampling points

- QA/QC data.

Project files will contain the following documents for each sampling event:

- $\quad$ Field measurements and logbooks

- Laboratory data packages, including, but not limited to, COC records, copies of sample tracking records, analysts' logbook pages, instrument logbook pages (including instrument conditions), bench sheets, instrument readout records, computer printouts, chromatographic charts, raw data summaries, correspondence and memorandums, and document inventory

- Data validation reports summarizing the validation process used and specific comments pertaining to a sample or group of samples

Additional details for data reporting will be included in the RFI Work Plan or SAP.

\subsubsection{Frequency of Internal Quality Control Checks and Laboratory Performance Audits}

The type and frequency of internal QC checks and the approach for evaluating these checks relative to project DQOs and data use objectives will be documented in the selected subcontractor laboratory SOP and included in the RFI Work Plan or SAP. Depending on the data collection activity, internal QA checks could include the following:

- $\quad$ Field-related blanks such as rinseate and trip blanks, as appropriate

- $\quad$ Field duplicates

- $\quad$ Matrix spike/Matrix spike duplicates (MS/MSDs)

- $\quad$ Standard analytical reference materials (SARMs) and audit samples

- $\quad$ Confirmation samples (sent to alternate laboratories)

In addition to these project QC checks, standard internal laboratory QC checks will be required (e.g., calibration checks, surrogate spikes, blanks, laboratory duplicates, laboratory control samples). The RFI Work Plan or SAP will define appropriate procedures for project and laboratory QC checks relative to the accuracy, precision, and completeness goals for the project. 
At this time, the Permittees are not considering performing a separate performance audit of the selected subcontractor laboratory.

\subsection{DATA MANAGEMENT PLAN}

This section of the FWP describes the general data management practices to be implemented under the RFI Work Plan or SAP at the WIPP site to document and track investigation data and results. More detail on the data management plan will be included in the RFI Work Plan or SAP. This Data Management Plan (DMP) includes a discussion of the expected data types to be generated during the RFI Work Plan or SAP activities: electronic data management procedures (including tabulated and map data storage), database interfaces, hard-copy data management procedures; data management responsibilities; and data flow. Data management practices for the RFI Work Plan or SAP will be based on the WIPP Records Management Program (WP 15-PR) and the WIPP Quality Assurance Program Description (WP 13-1).

\subsection{Data Documentation Materials and Procedures}

Data documentation materials generated under the RFI Work Plan or SAP will include field and laboratory notebooks, forms, and supporting information. This section discusses how each type of data is transferred into the project files.

Primary responsibility for data management activities under the RFI Work Plan or SAP will reside with the SWMU Project Manager. The SWMU Project Manager will designate other individuals from EC or other facility organizations (e.g., the Information Resource Management group) that will have access to the data and assist with data management activities. Additional QA oversight of data management activities will be performed by the QA Department.

Additional details on data documentation materials and procedures will be included in the RFI Work Plan or SAP.

\subsubsection{Field Data}

WIPP field personnel will complete COCs for samples collected. The original copy of the COC will be shipped with the samples, one copy will be provided to the SWMU Project Manager for sample tracking entry, and one copy will be retained in the files of the Sampling Team. The laboratory will also be required to maintain signed COCs and the bill of lading used to ship the samples to the laboratory. This information will be returned to the Permittees in the analytical data packages.

Other field documentation including field notes, and sampling data sheets will be reviewed for correct formatting, completeness, and accuracy of the information reported. Designated WIPP personnel will submit these documents to the SWMU Project Manager for entry of appropriate information into the database management system. After data entry is complete, the original field documents and a listing of the data entered in the database will be sent to the appropriate technical staff for review 
and approval. The original field documents and printouts of the entered data will then be filed in the project files.

\subsubsection{Analytical Data}

During sample analysis at the laboratory, analytical results will be either entered into the laboratory information management system (LIMS) or directly downloaded from the analytical instrument. The data will be reviewed in the laboratory for errors or omissions to ensure that the data are reported in the correct format. Upon completion of these efforts, the laboratory will submit electronic data deliverables and hard-copy raw data to the Permittees. Designated WIPP personnel will translate the electronic data into the proper database format (if necessary), check for incorrect information, and load the data into the database management system. The SWMU Project Manager will be notified of inconsistencies, omissions, or errors with the electronic data deliverables that require correction. The SWMU Project Manager will notify and work with the laboratory to correct the identified problems.

\subsection{Project File Requirements}

The project files and records generated by RFI Work Plan or SAP activities will be controlled and maintained in accordance with the record inventory and disposal system (RIDS) and the WIPP Records Management Plan (WP 15-PR). Complete, accurate, and auditable project records will be maintained. QA records for RFI Work Plan or SAP activities will be identified in the project-specific plans and procedures. As applicable, the use and management of the software and electronic data utilized for the RFI Work Plan or SAP activities will comply with the QA and documentation requirements established in the WIPP Quality Assurance Program Description (WP 13-1). Additional detail on project file requirements will be included in the RFI Work Plan or SAP.

\subsection{Project-Related Progress Reporting Procedures and Documents}

Once final data are checked and loaded into the RIDS, data users will be able to query the database, organize the data, perform numerical analysis, and produce hard-copy output for data interpretation and reporting. Possible output from the data management system could include the following:

- $\quad$ Tabular data: Tables of analytical results, statistical result summaries, summaries of samples collected and analyses performed, geologic and lithologic data tables, tables of risk-based screening criteria or risk assessment data.

- $\quad$ Graphical (map) data: SWMU location maps, sample location maps, boring logs, geologic cross sections, SWMU maps depicting the distributions of specific target constituents, site conceptual models, design drawings for corrective actions. 
Output from the data management system will be used to develop routine progress reports and project-specific reports for submittal according to Permit requirements. Additional detail on project-related progress reporting procedures and documents for specific RFI Work Plan or SAP activities will be included in the RFI Work Plan or SAP.

\subsection{Data Records}

The scope of work for the RFI Work Plan or SAP has not been finalized. More information on expected data records will be included in the final document. At this time, the additional data collection activities anticipated under the RFI Work Plan or SAP include:

- $\quad$ Soil sampling and analysis

- $\quad$ Locating sample locations

- Investigation-derived material handling

The data record for each sample and field measurement will include at least the following information: unique measurement code, measurement location, measurement type, laboratory identification number, property or component analyzed, and results of analysis. Data and documentation from RFI Work Plan or SAP activities are expected to be compiled and processed in electronic and hard-copy forms.

\subsubsection{Electronic Data}

Electronic data can be divided into two categories: data tables and graphical (map) data. Data generated during the RFI Work Plan or SAP activities will be managed using a database management system that provides an effective framework to handle the existing and anticipated data. In addition to meeting the needs of data users, the database management system will incorporate the following capabilities:

- $\quad$ Store tabular data (such as analytical results, data qualifiers, and boring log data)

- $\quad$ Store graphical data map data (such as cultural features, sample location, and other spatial features) using appropriate graphical software (such as AutoCAD), or in a spatial database (commonly referred to as a Geographic Information System [GIS])

- $\quad$ Additional information on the format to be used to present the data and conclusions of the investigation will be included in the RFI Work Plan or SAP.

\subsubsection{Tables}

Tabular data include data formatted as rows and columns and stored in tables of an electronic spreadsheet or relational database. Tabular data will include raw data, data sorted by significant features (e.g., location, media, constituent), data reduction for statistical analysis, and summary data. 
Given the possible field activities discussed above, the following types of electronic tabular data may be generated or processed during RFI Work Plan or SAP activities:

- $\quad$ Sample identification information

- $\quad$ Analytical data

- $\quad$ Soil boring data

- $\quad$ Sample location/survey data

- $\quad$ Analytical results

- $\quad$ Numerical analysis results (e.g., statistics)

- Investigation-derived material tracking data

The format and specific records for the data tables will be included in the RFI Work Plan or SAP. Electronic data in tabulated format will be stored and retrieved through a spreadsheet program or a relational database program.

\subsubsection{Graphical Formats}

Graphical formats for data presentation include both summaries of results and map data. Sampling, analytical, and numerical results may be presented in bar graphs, line graphs, and other data presentations and be stored with the tabular data. Map data are information more appropriately stored in a graphical format than in a tabular format. Storage of the following types of electronic map data is possible for the RFI Work Plan or SAP:

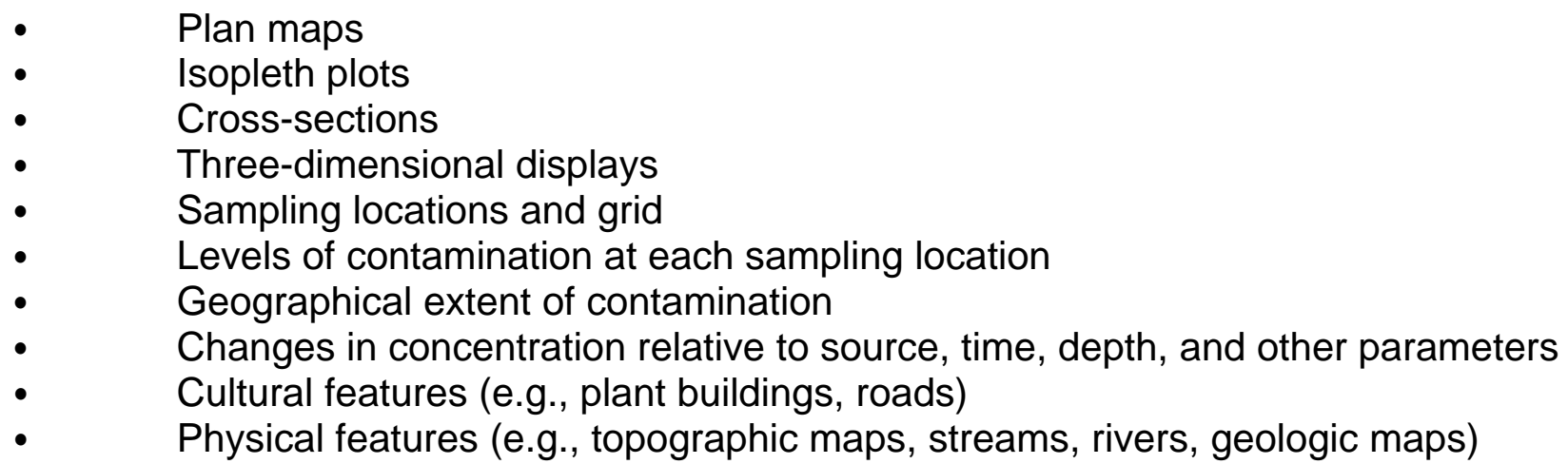

Electronic data of mapped features will be stored as graphical data or in a spatial database format. The specific map data to be stored will be defined in the RFI Work Plan or SAP.

\subsubsection{Hard-Copy Data}

Hard-copy data are generated during investigation activities to document the work that was performed. Additional hard-copy data will be generated from the electronic data described above. Examples of hard-copy data include field notes, boring logs, COC forms, analytical data packages, and investigative-derived material (IDM) tracking forms. Section 4.2 of this plan discusses the procedures that will be used to store hardcopy data, which will be based on facility record management requirements. In addition 
to filing the hard-copy forms in the project files, information will be entered from hardcopy forms into the project database when appropriate. Many documents will be gathered, transferred, and generated during the RFI investigations. The term "document" refers to relevant information in hard-copy form (i.e., plans, reports, correspondence, raw and validated analytical data, field notes, maps, figures, models, etc.). Documents gathered or generated in support of the RFI Work Plan or SAP will be stored in a central project file administered by the SWMU Project Manager in accordance with the facility RIDS and the WIPP Records Management Plan (WP 15-PR). QA records generated by specific activities will be documented in the RFI Work Plan or SAP.

\subsection{Sample Data Tracking}

A reliable sample tracking system is essential to assure the maintenance of environmental data integrity. Environmental samples will be tracked using a sample tracking database in combination with a filing system and other procedures that will be specified in the RFI Work Plan or SAP. The effectiveness of the system will be verified through periodic audits. Audits of the data base records will include tracking of data collected during field activities and a review of the data stored in the database. These audits, conducted by the SWMU Project Manager, or designated representative, will consist of following the flow of a portion of data completely through the hard-copy and electronic systems. In addition, a small portion of the data in the database will be periodically checked against original information. Access to the sample tracking database will be limited to the SWMU Project Manager and designated personnel, who are responsible for sample tracking. The sample tracking database will consist of a table within the general electronic database and will include fields such as:

$\begin{array}{ll}\text { - } & \text { Sample identification } \\ \text { - } & \text { Container } \\ \text { - } & \text { Sample volume } \\ \text { - } & \text { Sample matrix } \\ \text { - } & \text { Analysis requested } \\ \text { - } & \text { Sample date } \\ \text { - } & \text { Dequested turnaround time } \\ \text { - } & \text { Date data validated/reviewed } \\ \text { - } & \text { Date of electronic data QC check } \\ & \text { Invoice status }\end{array}$

Using the sample tracking database, the SWMU Project Manager or designee will track sample progress through sampling and analysis; log-in data received from the field or subcontractor laboratories; check that COCs and hardtop data have been filed; resolve data discrepancies with the laboratory; and transfer approved data to data users and reviewers. Data gaps will be identified, and the resolution of the data gaps will be documented. 


\subsection{SITE SAFETY AND HEALTH PLAN}

This section contains the Site Safety and Health Plan for RFI Work Plan or SAP activities. Section VII.U.3.h of the Permit requires that the site safety and health plan for the facility include the following:

a. A description of the facility including availability of resources such as roads, water supply, electricity, and telephone service

b. A description of the known hazards and evaluation of the risks associated with each activity conducted, including but not limited to on- and off-site exposure to contaminants during implementation of interim measures

c. A list of key personnel and alternatives responsible for site safety, response operations, and for protection of public health

d. A delineation of the work area

e. A description of levels of protection to be worn by personnel in the work area

f. Procedures established to control site access

g. Decontamination procedures for personnel and equipment

h. Site emergency procedures

i. Emergency medical care procedures for injuries and toxicological problems

j. Requirements for an environmental field monitoring program

k. Routine and special training requirements for responders

I. Procedures for protecting workers from weather-related problems

Each of these items is described in this section.

\subsection{Facility Description}

The WIPP facility provides surface structures to accommodate personnel, equipment, and support services. These surface structures serve the operational functions of the WIPP and are available to support any RFI Work Plan or SAP activities. The surface facilities are located in the Property Protection Area of approximately 34 acres within the perimeter fence. The principal surface structure is the Waste Handling Building; other surface structures include hoist houses, the Support Building, the Guard and Security Building, office trailers, the Exhaust Filter Building, warehouse and shops, the Water Pump House, the Training Building, the Engineering Building, the Core Storage Building, and the Safety and Emergency Services Building. 
Access to the WIPP facility is provided by two access roads that connect with U.S. Highway 62/180, 13 miles to the north, and NM Highway 128 (Jal Highway), 4 miles to the south. The northern access road, which connects the site to U.S. Highway 62/180, was built specifically for the DOE. The southern access road is a county highway maintained by Eddy County. Rail access is from the west across the southern access road. Access to the facility for personnel, visitors, and vehicles is provided through a security checkpoint (vehicle trap). Numerous graded roads are available throughout the WIPP site. These are generally single lane, packed caliche roads. They are used to access remote areas of the site for the purposes of monitoring. These roads are adequate to handle the heaviest equipment that is anticipated for use during RFI activities.

The primary function of the WIPP facility water system is to supply water for domestic use and fire protection. The Double Eagle Water Company, owned by the City of Carlsbad, furnishes water. Wells located 30 miles north of the WIPP facility are the source of the water. Water is supplied by gravity flow through a 24-inch diameter pipeline to a junction point about 13 miles north of the site at U.S. Highway 62/180. This line is sized to provide 6,000 gallons per minute for use by others, in addition to the peak flow rate required by the WIPP facility. Controls at the junction point give the WIPP facility priority over flows to all other users. A 10-inch diameter pipeline supplies water by gravity flow from the tie-in point to the WIPP facility.

At the WIPP facility, the water enters a pair of 180,000-gallon, aboveground storage tanks located adjacent to the Pumphouse. These tanks are 32 feet in diameter and are constructed of welded steel. The water level in each tank is monitored in the CMR. Of the 360,000 -gallon total capacity, about 160,000 gallons (80,000 gallons per tank) are designated for storage of a two-day supply of domestic water. At least 180,000 gallons of the remaining 200,000 gallons of water are dedicated to fire suppression and are sufficient to handle the maximum credible fire. Separate sets of pumps for the domestic water and fire-water systems are provided in the Pumphouse. During a fire, the firewater pump is automatically started, and available domestic water is used first. Upon depletion of the domestic-water inventory, the domestic-water pumps are automatically shut off, and the dedicated fire-water reserve is available for fire-suppression use only. The primary fire-water pump is a 100-percent-capacity electric pump. A 100-percentcapacity diesel fire-water pump provides backup in case of a power failure or when maintenance is required on the electric pump. Each fire-water pump is rated at 1,500 gallons per minute at 125 pounds per square inch.

Electricity is purchased from a local utility and is delivered to the WIPP site via a power line that feeds from both the north and the south. In the event that normal utility power is lost, on-site diesel generators will provide alternating current (AC) power to important WIPP facility electrical loads. Uninterruptible power supply (UPS) units are also on-line, providing power to important monitoring systems.

In case of a loss of utility power, backup power to predetermined loads can be supplied by either of the two on-site diesel generators. Each of these units provides 480 volts (V) 
of power with a high degree of reliability and is sized to feed the selected loads. The diesel generators can be brought on-line within 30 minutes.

The intraplant communication system is designed to provide day-to-day communications and immediate emergency instructions to facility personnel. It includes two-way communication by the public address (PA) system and its intercom phones and paging channels, a telephone system, mine phones, pagers and plectrons, portable two-way radios, and local and facility-wide alarm systems.

The intercom system (with an integral PA system) consists of handset stations and loudspeaker assemblies, with multiple amplifiers. The system has multiple channels in the main buildings. Initial communication between parties within the plant can be established by using the paging channel. Each designated location has a single set of electrically isolated speakers and a handset. In order to cover most areas in the plan, loudspeakers are properly oriented, and volume levels are adjusted. If one station fails, the remaining stations are isolated from the out-of-service unit to prevent a failure in the remaining system.

Private branch automatic exchange two-way communication is provided between any two telephones located above or below ground. Direct dialing to outside telephones and direct dialing to WIPP facility telephones are provide by this system. Failure of a single telephone station does not affect the balance of the telephone system. If the telephone system should fail, the PA system, the plectrons, and the portable two-way radios provide backup surface communications.

The Site Notification System (SNS) consists of pagers in the possession of office wardens and plectrons located in various buildings. The SNS pagers and plectrons are tone-activated radio receivers that are activated by the two-way radio system. To generate a tone on the pagers and plectrons or to send a verbal message, the radio operator enters a security code into the two-way radio system and begins broadcasting. The SNS pagers are portable and battery-operated. The plectrons are portable and can be plugged into a standard electrical circuit or powered from internal batteries that are continuously recharged when connected to the electrical circuit.

A plant radio station in the Guard and Security Building, one located in the Emergency Operations Center in the Safety and Emergency Services Building, and one in the Central Monitoring Room (CMR), allow two-way radio communication with on-site personnel and with mobile/portable WIPP facility radios operating on and off the WIPP site. The two-way radio also allows one-way emergency notification on the portable SNS pagers and plectrons. The two-way radio system located in the CMR is supplied with power from the uninterruptible power supply if the off-site power supply fails.

\subsection{Description of Known Hazards and Evaluation of Risks}

Prior to any work being performed, a job hazard analysis by will be performed by the Industrial Safety and Hygiene (ISH) Section to evaluate known hazards and risks associated with each activity. Safe work permits (SWPs) are prepared to assure that 
any hazardous work (not already covered by a procedure) is performed with due precaution. The WIPP ISH Section issues SWPS after a job supervisor completes the proper form detailing the job location, work description, personnel involved, specific hazards involved, and protective requirements. The ISH personnel review the form, check on the adequacy of the protective measures, and if sufficient, approve the work permit. Conditions of the SWPs must be met while any hazardous work is proceeding. Examples of activities covered by the SWP program include confined space entry, overhead work, and work on energized equipment.

Safety assessments were completed during the Voluntary Release Assessment Program (DOE/WIPP 96-2209) and no chemical safety concerns were identified. No off-site exposure to contaminants during implementation of interim measures is anticipated, because no interim measures are anticipated for the RFI Work Plan or SAP.

\subsection{Key Personnel}

A number of WIPP personnel will be involved in fulfilling the RFI Work Plan or SAP. The SWMU Project Manager from Environmental Compliance (EC) will be responsible for coordinating activities related to the RFI Work Plan or SAP. The SWMU Project Manager will marshal and monitor needed resources for the program and serve as liaison between other cognizant organizations. The SWMU Project Manager will report to the DOE through the Environmental Safety and Health (ES\&H) manager.

Other organizations that may be involved in the field portion of the RFI Work Plan or SAP activities include: the Sampling Team, Industrial Safety and Hygiene (for health and safety issues), and subcontractors. The actual involvement of these organizations and their direct responsibilities will be solicited as needed by the SWMU Project Manager. Responsible organizations and individuals will be specified as part of the RFI Work Plan or SAP.

\subsection{Delineation of Work Area}

It is not possible at this time to delineate the work area for the investigation at each SWMU and AOC that will be included in the RFI Work Plan or SAP. Grab samples of soil will be collected at discrete location within and near the SWMUs and AOCs. The sampling team leader will be responsible for identifying sampling locations and identifying any necessary exclusion areas for personnel.

\subsection{Levels of Personnel Protection}

The ISH Section provides assistance in defining hazards associated with particular activities and in defining appropriate safety precautions and personal protective equipment (PPE) for specific job assignments. Safety assessments were completed during the Voluntary Release Assessment program (DOE/WIPP 96-2209) and no chemical safety concerns were identified. For anticipated activities at the SWMUs and AOCs, it is likely that Level D PPE will be specified (i.e., steel toe boots, safety glasses, work gloves, and hard hat if appropriate). 


\subsection{Procedures for Site Access Control}

Attachment $\mathrm{C}$ of the WIPP Permit defines site access and security procedures. For each SWMU and AOC sampled, the sampling team leader will be responsible for restricting access to the sampling locations.

\subsection{Decontamination Procedures for Personnel and Equipment}

Safety assessments were completed during the Voluntary Release Assessment program (DOE/WIPP 96-2209) and no chemical safety concerns were identified that suggest that personnel decontamination procedures will be required. Equipment decontamination procedures will be initiated to prevent cross contamination between samples (see Section 3.2.7 of this FWP).

\subsection{Site Emergency Procedures}

The WIPP Permit (Attachment F) and the WIPP Emergency Management Plan describe site emergency procedures applicable to RFI Work Plan or SAP activities. If RFI Work Plan or SAP planning indicates that these procedures are not adequate, additional procedures will be identified in the RFI Work Plan or SAP.

\subsection{Emergency Medical Care Procedures}

The WIPP Permit (Attachment F) and the WIPP Emergency Management Plan describe site emergency medical care procedures applicable to RFI Work Plan or SAP activities. If RFI Work Plan or SAP planning indicates that these procedures are not adequate, additional procedures will be identified in the RFI Work Plan or SAP. In addition, the General Employee Training for the site describes emergency medical care procedures.

\subsection{Environmental Field Monitoring Program}

No environmental field monitoring program is anticipated for the RFI Work Plan or SAP. RFI Work Plan or SAP activities will be restricted to collecting soil samples. No personnel exposure to other constituents is anticipated. This requirement will be reevaluated as part of the RFI Work Plan or SAP.

\subsection{Routine and Special Training Requirements for Responders}

At WIPP, responders require Hazardous Waste Worker and Hazardous Waste Responder training. No special training requirements are anticipated for RFI Work Plan or SAP activities.

\subsection{Procedures for Protecting Workers from Weather-Related Problems}

Prior to leaving for off-site sampling activities, sampling personnel will sign out from their designated work locations to indicate their off-site sampling location. The sampling team leader will receive a cellular telephone, a pager, or a portable radio, whichever is 
most efficient for off-site communication and notification. In the event that site personnel identify weather-related problems, this information can be transmitted to the sampling team. If the sampling team identifies weather-related problems, the information can be transmitted to the site. In either case, sampling personnel will take appropriate shelter in the field, or return to the site.

\subsection{Additional Considerations}

Procedures for delineating the RFI Work Plan or SAP activity work area, decontamination procedures, and requirements for environmental monitoring programs and other safety-related issues potentially applicable to RFI Work Plan or SAP activities as required by the Permit are contained in the following existing WID documents:

Quality Assurance Project Plan for WIPP Site Effluent and Hazardous Materials Sampling (WP 02-EC.05)

WIPP Site Effluent and Hazardous Materials Sampling Plan (WP 02-EC.06) WIPP Chemical Hygiene Plan (WP 12-IH.01)

WIPP Industrial Hygiene Program (WP 12-IH.02)

Industrial Safety Program (WP 12-IS.01)

Fire Prevention Program (WP 12-FP.01)

Applicable requirements from these documents necessary for the investigations will be explicitly included in the RFI Work Plan or SAP. In addition, the specific information required by Permit Condition VII.U.3.h (1) will be included in the RFI Work Plan or SAP. The SWMU Project Manager will verify that appropriate health and safety activities are coordinated with other organizations and incorporated into the investigations.

\subsection{Consistency with Other Programs}

At the WIPP site, safety is each individual's responsibility. The facility has an exemplary safety culture. As required by Permit condition VII.U.3.h.(2), the safety and health program in place at WIPP is consistent with DOE, National Institute for Occupational Safety and Health (NIOSH), Occupational Safety and Health Administration (OSHA), Mine Safety and Health Administration (MSHA), EPA requirements, and state and local regulations. Additional detail on the Site Safety and Health Plan will be included in the RFI Work Plan or SAP.

\subsection{COMMUNITY RELATIONS PLAN}

This community relations plan addresses issues relevant to the public regarding dissemination of information on future investigation activities and results for the SWMUs/AOCs. Section VII.U.3.i of the Permit includes the following requirements for community relations during the RFI Work Plan or SAP activities: 
- $\quad$ Obtain an initial facility mailing list of interested persons and entities from NMED and update it semiannually

- Hold informal meetings, briefings and workshops as appropriate with the public and local officials

- $\quad$ Prepare and disseminate news releases, fact sheets, RFI Work Plan or SAP, RFI reports, Special Permit Conditions Reports, and publicly available quarterly progress reports

- $\quad$ Create public information repositories and reading rooms in Sante Fe, Albuquerque, and Carlsbad, New Mexico

- $\quad$ Update materials in the repositories and reading rooms as appropriate

- $\quad$ Prepare quarterly technical progress reports for NMED

- $\quad$ Establish procedures for immediate notification of affected persons or entities which could be impacted by newly discovered off-site releases from the SWMUS/AOCs

\subsection{Facility Mailing List}

The initial facility mailing list was obtained from NMED on December 17, 1999. Additions to this list are provided to NMED prior to each mailing. Likewise, any NMED updates to the mailing list are requested prior to each mailing. Formal notification of changes to the mailing list will be made in accordance with the permit. The RCRA Permitting group will maintain this mailing list.

\subsection{Informal Meetings}

Informal meetings, including briefings and workshops as appropriate, will be held with the public and local officials before and during the RFI process if requested by the public or NMED. These meetings will discuss activities associated with the RFI Work Plan or SAP and RFI Report.

\subsection{News Releases, Fact Sheets, Approved RFI Work Plans, RFI Reports, Special Permit Conditions Reports, and Quarterly Progress Reports}

If requested by NMED, the Permittees will prepare news releases and fact sheets describing the availability approved RFI Work Plans, RFI Reports, Special Permit Condition reports, and publicly available quarterly progress reports which explain the progress and conclusions of the RFI. At this time, the Permittees will notify each individual on the mailing list regarding the availability of documents required by the Permit. 
The Permittees public affairs organizations may assist in preparation and dissemination of required news releases.

\subsection{Information Repositories}

As required by the Permit (VII.D, and VII.U.3.i.(4)), DOE has established information repositories in Sante Fe (New Mexico State Library), Albuquerque (University of New Mexico Zimmerman Library), and in Carlsbad (Skeen-Whitlock Building).

A notice, approved by NMED, was sent to all individuals on the list December 21, 1999, describing the location, purpose and contents of the information repositories. In addition, the notice described the schedule for submitting written comments to NMED regarding documents placed in the repositories. As required by the Permit, these activities were completed within 30 days of the effective date of the Permit (November 26, 1999).

In the future, deliverables and correspondence produced as part of the RFI Work Plan or SAP activities will be placed in the repositories on or before the date due to NMED. These documents may include: approved work plans or SAPs, technical reports, and progress reports. At least five days before each submittal is due to NMED and placed in the repository, a written notice will be mailed to each individual on the current facility mailing list describing the submittal and indicating the date the submittal will be available for review at the repositories.

\subsection{Updates of Materials in the Information Repositories and Reading Rooms}

To the extent necessary, the Permittees will update materials in the information repositories. Routine updates will occur as Permit required documents are completed and submitted to the repositories.

\subsection{Quarterly Technical Progress Reports}

Quarterly technical progress reports will be prepared and submitted to NMED and placed in the Information Repositories regarding the RFI Work Plan or SAP activities in accordance with Section VII.I (and VII.U.3.i.(6)) of the Permit.

\subsection{Immediate Notifications}

Although it is unlikely that newly discovered off-site releases will be identified from these SWMUS/AOCs, plans exist for immediate notification to nearby residents of such releases. The RCRA Contingency Plan contained in Attachment F of the Permit identifies the WIPP incident response personnel and responsibilities and the plans and procedures for notifications of site-related incidents. To the extent necessary, the requirements of the RCRA Contingency Plan will be included in the RFI Work Plan or SAP for community relations. Those portions of the contingency plan germane to the RFI Work Plan or SAP will be explicitly included in the plan and will be implemented in the event that such off-site releases are discovered. 


\subsection{REFERENCES}

40 CFR 260-270: Environmental Protection Agency (EPA) Regulations Implementing the Resource Conservation and Recovery Act (RCRA)

20 NMAC 4.1, Hazardous Waste Management

New Mexico Environment Department, 1994. Assessment of Solid Waste Management Units at the Waste Isolation Pilot Plant, the WIPP RCRA Facility Assessment (RFA), (NMED/DOE/AIP 94/1), May.

New Mexico Environment Department, 1998. HRMB Standard Operating Procedures Manual, March.

New Mexico Environment Department, 1999a. Waste Isolation Pilot Plant Hazardous Waste Permit, NM4890139088-TSDF, October 27.

New Mexico Environment Department, 1999. Technical Support Document, Exclusion/Inclusion of Solid Waste Management Units and Areas of Concern, Permit Module VII Corrective Action for Solid Waste Management Units. Waste Isolation Pilot Plant EPA No. NM4890139088. October.

U.S. Congress, 1992. Public Law 102-579, Waste Isolation Pilot Plant Land Withdrawal Act. 102nd Congress, Washington, D.C. October.

U.S. Department of Energy, 1991. WIPP RCRA Part B Permit Application, DOE/WIPP 91-005, Revision 0.

U.S. Department of Energy, 1995. WIPP RCRA Part B Permit Application, DOE/WIPP 91-005, Revision 6.

U.S. Department of Energy, 1996. Final Voluntary Release Assessment/Corrective Action Report, DOE/WIPP 96-2209.

U.S. Department of Energy, 1997a. Supplemental Information Requested by the New Mexico Environment Department for Solid Waste Management Units, DOE/WIPP 97-2220a.

U.S. Department of Energy, 1997b. Using the Data Quality Objectives Process During the Design and Conduct of Ecological Risk Assessments, DOE/EH-0544, Washington, D.C., February.

U.S. Environmental Protection Agency, 1983a. Interim Guidelines and Specifications for Preparing Quality Assurance Management Plans - QAMS-005/80.

U.S. Environmental Protection Agency, 1983b. Methods for Chemical Analysis of Water and Wastes, March. 
U.S. Environmental Protection Agency, 1984. Guidelines Establishing Test Procedures for the Analysis of Pollutants Under the Clean Water Act. Final Rule and Proposed Rule, 40 CFR Part 136, October.

U.S. Environmental Protection Agency, 1987. Data Quality Objectives for Remedial Response Activities (Development Process): USEPA/540/G-87/003, Office of Emergency and Remedial Response, Washington, D.C., March.

U.S. Environmental Protection Agency, 1989a. RCRA Facility Investigation Guidance Document, Volumes I-IV, EPA 530/SW-89-031, May.

U.S. Environmental Protection Agency, 1989b. Risk Assessment Guidance for Superfund, Volume II, Environmental Evaluation Manual, Office of Emergency and Remedial Response, Washington, D.C., EPA/540/1-89/001.

U.S. Environmental Protection Agency, 1990. Corrective Actions for Solid Waste Management Units at Hazardous Waste Management Facilities, Proposed Rule, Federal Register, Vol. 55, No. 145, July 27, 1990.

U.S. Environmental Protection Agency, 1992. Framework for Ecological Risk Assessment. Risk Assessment Forum, Washington, D.C., EPA/630/R-92/001.

U.S. Environmental Protection Agency, 1993. Data Quality Objectives Process for Superfund, Interim Final Guidance, September, EPA540-R-93-071.

U.S. Environmental Protection Agency, 1994a. RCRA Corrective Action Plan, Final, Office of Solid Waste and Emergency Response (OSWER), OSWER Directive 9902.3-2A, May.

U.S. Environmental Protection Agency, 1994b. Guidance for the Data Quality Objectives Process. Quality Assurance Management Staff, Washington, D.C. EPA QA/G-4.

U.S. Environmental Protection Agency, 1994c. USEPA Contract Laboratory Program National Functional Guidelines for Inorganic Data Review, EPA 540/R-94/013 February.

U.S. Environmental Protection Agency, 1996. Proposed Guidelines for Ecological Risk Assessment; Notice. Federal Register Vol. 61, No. 175, Monday September 9, 1996.

U.S. Environmental Protection Agency, 1997a. Ecological Risk Assessment Guidance for Superfund: Process for Designing and Conduction Ecological Risk Assessments, Interim Final, Environmental Response Team, Edison, N.J., June.

U.S. Environmental Protection Agency, 1997b. Test Methods for Evaluating Solid Waste, Office of Solid Waste and Emergency Response SW-846, December (incorporating earlier revisions dated 1986, 1992, and 1994). 
U.S. Environmental Protection Agency, 1998a. Guidance for Data Quality Assessment, Practical methods for Data Analysis, EPA QA/G-9. January.

U.S. Environmental Protection Agency, 1998b. Guidelines for Ecological Risk Assessment; Notice. Federal Register Vol. 63, No. 93, Thursday May 14, 1998.

U.S. Environmental Protection Agency, 1998c. EPA Guidance for Quality Assurance Project Plans for Environmental Data Operations, EPA QA/R-5. February.

U.S. Environmental Protection Agency, 1999a. USEPA Contract Laboratory Program Statement of Work for Inorganic Analysis and Classical Chemistry Parameters, Multi-media, Multi-concentration, ILM05.0C. March.

U.S. Environmental Protection Agency, 1999b. USEPA Contract Laboratory Program Statement of Work for Organics Analysis, Multi-media, Multi-concentration, OLM04.2. May.

U.S. Environmental Protection Agency, 1999c. USEPA Contract Laboratory Program, National Functional Guidelines for Organic Data Review - EPA540/R-99/008. October.

Waste Isolation Pilot Plant Hazardous Waste Permit, New Mexico Environment Department, October 27, 1999

WIPP Land Management Plan, DOE/WIPP 93-004

WP 02-EC.05, Quality Assurance Project Plan for WIPP Site Effluent and Hazardous Materials Sampling

WP 02-EC.06, WIPP Site Effluent and Hazardous Materials Sampling Plan

WP 12-FP.01, Fire Protection Program

WP 12-IH.01, WIPP Chemical Hygiene Plan

WP 12-IH.02, WIPP Industrial Hygiene Program

WP 12-IS.01, Industrial Safety Program

WP 13-1, WID Quality Assurance Program Description

WP 15-PR, WIPP Records Management Program 